Georgia State University

ScholarWorks @ Georgia State University

2016

\title{
Transgender Adults' Access to College Bathrooms and Housing and the Relationship to Suicidality
}

Kristie L. Seelman

Georgia State University, kseelman@gsu.edu

Follow this and additional works at: https://scholarworks.gsu.edu/ssw_facpub

Part of the Social Work Commons

\section{Recommended Citation}

Seelman, Kristie L., "Transgender Adults' Access to College Bathrooms and Housing and the Relationship to Suicidality" (2016). SW Publications. 64.

https://scholarworks.gsu.edu/ssw_facpub/64

This Article is brought to you for free and open access by the School of Social Work at ScholarWorks @ Georgia State University. It has been accepted for inclusion in SW Publications by an authorized administrator of ScholarWorks@ Georgia State University. For more information, please contact scholarworks@gsu.edu. 
Transgender Adults' Access to College Bathrooms and Housing and the Relationship to Suicidality

Kristie L. Seelman, PhD, MSW

School of Social Work, Andrew Young School of Policy Studies, Georgia State University, Atlanta, Georgia, USA

The Version of Record of this manuscript has been published and is available in the Journal of Homosexuality, as of February 25, 2016, at http://www.tandfonline.com/10.1080/00918369.2016.1157998

Author Note

Thanks to Dr. K. Jurée Capers for reviewing a draft of this manuscript and offering constructive feedback.

The National LGBTQ Task Force and the National Center for Transgender Equality conducted the National Transgender Discrimination Survey, which generated the data analyzed within this study. Their report on the survey data is available at http://www.thetaskforce.org. 
Correspondence concerning this article should be addressed to Kristie L. Seelman, School of Social Work, Andrew Young School of Policy Studies, Georgia State University, PO Box 3995, Atlanta, GA 30302-3995. E-mail: kseelman@ gsu.edu 


\begin{abstract}
Transgender and gender non-conforming people frequently experience discrimination, harassment, and marginalization across college and university campuses (Bilodeau, 2007; Finger, 2010; Rankin, et al., 2010; Seelman et al., 2012). The minority stress model (Meyer, 2007) posits that experiences of discrimination often negatively impact the psychological well-being of minority groups. However, few scholars have examined whether college institutional climate factors - such as being denied access to bathrooms or gender-appropriate campus housing — are significantly associated with detrimental psychological outcomes for transgender people. Using the National Transgender Discrimination Survey, this study analyzes whether being denied access to these spaces is associated with lifetime suicide attempts, after controlling for interpersonal victimization by students or teachers. Findings from sequential logistic regression $(N=2,316)$ indicate that denial of access to either space had a significant relationship to suicidality, even after controlling for interpersonal victimization. This paper discusses implications for higher education professionals and researchers.
\end{abstract}

Key words: bathrooms, campus housing, harassment, higher education, minority stress model, suicidality, transgender 


\section{Transgender Adults' Access to College Bathrooms and Housing and the Relationship to Suicidality}

At a time when there is rising public awareness of transgender ${ }^{1}$ identities, we are at a critical moment for examining the ways our institutions, including colleges and universities, can best be structured to meet the needs of transgender people. Over the past few decades, a growing proportion of the U.S. population has been attending college, making this an important institutional setting for many. While in $1960,45.1 \%$ of adults with a recent high school diploma or GED were enrolled in college, by 2013 this number had risen to $65.9 \%$ (U.S. Department of Education, 2014a). Recent guidance from the U.S. Department of Education (2014b) has indicated that transgender people are included as part of Title IX protections against discrimination and violence, which has an impact on colleges and universities receiving federal financial assistance. Institutions of higher education need to be prepared for meeting the needs of a diverse population of adults.

An established body of literature indicates that lesbian, gay, bisexual, and transgender people's health and well-being is connected to internalized stigma, expected prejudice, and interpersonal violence and discrimination (Meyer, 1995, 2003). Transgender people have elevated rates of suicide ideation and attempts compared to the general population (SAMHSA, 2012), and recent research suggests that transgender college students are more likely to have experienced self-injury, suicide ideation, and suicide attempts compared to cisgender (non-transgender) students (Effrig, Bieschke, \& Locke, 2011). Further, among transgender adults, experiences of discrimination and victimization are associated with suicide attempts (Clements-Nolle, Marx, \& Katz, 2006; Goldblum et al., 2012; Testa et al.,

\footnotetext{
${ }^{1}$ Within the present study, transgender encompasses those whose gender identity differs from predominant cultural expectations for their sex assigned at birth. This includes people who undergo medical treatment to transition from one gender to another, as well as those who have not or will not undergo such treatment, and is meant to match the definition used by the organizations that conducted the National Transgender Discrimination Survey (Grant et al., 2011). I will often use the term trans* to denote inclusion of a broader range of gender non-conforming identities, including those who may not use the term transgender for themselves.
} 
2012). While the campus climate literature has been specifying best practices for serving transgender students, staff, and faculty for some time, seldom have various institutional practices been studied quantitatively in relationship to psychosocial outcomes for transgender people.

This article uses the National Transgender Discrimination Survey (NTDS), which is the largest survey of transgender individuals conducted in the U.S., to study whether denial of access to bathrooms and gender-appropriate campus housing are related to a heightened risk for suicide attempts among trans* individuals. This paper will first provide an overview of previous research about trans* people's experiences within higher education settings, followed by a description of the minority stress model. I will then detail the study's methods and results, concluding with a discussion of the findings and implications for higher education professionals and researchers.

\section{Experiences of Trans* People within Colleges and Universities}

Most research that has examined the experiences of lesbian, gay, bisexual, transgender, queer, and questioning (LGBTQ) people in higher education has focused predominately on gay or lesbian individuals, incorporating only small subsamples of transgender people, if any. However, what has been garnered from research-to-date is that discrimination, harassment, invisibility, and marginalization are common experiences for trans* people in colleges and universities (Bilodeau, 2007; Finger, 2010; Rankin, Weber, Blumenfeld, \& Frazer, 2010; Seelman, 2013; Seelman et al., 2012). The types of institutional and social support and affirmation that can contribute to resilience, coping, and academic success among trans* people are often lacking in college settings (Bilodeau, 2005; Dugan, Kusel \& Simounet, 2012; Singh, Meng, \& Hansen, 2013).

Further, trans* individuals are at risk for interpersonal victimization in college, including hostility, discrimination, harassment, and violence. In a national campus climate 
survey of over 5,000 LGBTQQ students, staff, and faculty including 695 trans* respondents (Rankin et al., 2010), harassment was more commonly experienced by the trans* participants (over $30 \%$ for each trans* identity group, compared to about $20 \%$ of either cisgender men or women). Trans* respondents were also significantly more likely to consider leaving their university, to be afraid for their safety, and to stay away from LGBTQQ spaces on campus, and less likely to agree that their institution offers acceptable levels of support to LGBTQQ people or effectively responds to LGBTQQ harassment. Additionally, trans* people of color were more likely than cisgender people of color to experience harassment. Respondents of color in general were also more likely to experience race as a basis of harassment than White respondents, indicating the overlapping nature of exclusion on campuses (Rankin et al., 2010). Other studies looking at experiences of transphobia across settings find similar patterns whereby trans* people are at differing risks by race and social class (Lombardi, 2009).

A recent national study (Dugan, Kusel, \& Simounet, 2012) that compared matched samples of transgender and cisgender college students found significantly different perceptions of the campus climate, with transgender students experiencing greater harassment and discrimination and having less of a sense of belonging. This study also looked at withingroup differences among the transgender sample and found that, while most measures of campus climate, engagement, and educational outcomes were similar between gender groups, male-to-female (MTF) transgender students and intersex students both experienced significantly less mentoring from faculty than other trans* students.

The National Transgender Discrimination Survey (NTDS), which was conducted by the National LGBTQ Task Force (the Task Force) and National Center for Transgender Equality (NCTE) and generated the dataset used for the present study, collected information from transgender and gender non-conforming adults throughout the U.S. about experiences in 
a variety of settings, including college. While this survey had a number of important drawbacks (discussed in the Limitations section of this article), the NTDS is one of the largest surveys of trans* adults conducted in the U.S. to date and thus offers an important source of data on this population. Based on findings from this survey, some of the correlates of harassment and/or assault in K-12 and/or college included greater likelihood of substance abuse, suicide attempts, homelessness, engaging in sex work for income, being imprisoned, being currently unemployed, and having a lower income (Grant et al., 2011). More than half (51\%) of those who were victimized in school had attempted suicide at some point in time, with even higher rates for people who were harassed or bullied by teachers (59\%), physically assaulted (64\%), sexually assaulted (68\%), sexually assaulted by teachers (69\%), or physically assaulted by teachers (76\%) (Grant et al., 2011).

While such evidence indicates the stark frequency of interpersonal victimization affecting transgender people in college and other educational settings, the environment of the college institution itself can make life more difficult for trans* people. Unlike physical or sexual assault or verbal harassment directed at trans* people, the ways we construct campus spaces might not be done with purposeful intention to harm trans* people. Yet, research indicates that the characteristics, norms, practices, and spaces of institutional environments can greatly affect trans* people's well-being (Beemyn \& Rankin, 2011; Bilodeau, 2007; Case, Kanenberg, Erich, \& Tittsworth, 2012; Finger, 2010; McKinney, 2005; Seelman, 2013, 2014a).

Trans* people have reported bathroom access as one of their most pressing challenges related to the college climate (Bilodeau, 2007; Finger, 2010). Negative bathroom experiences include being questioned about whether one belongs in the men's/women's bathroom (Bilodeau, 2007; Seelman et al., 2012), being stared at (Bilodeau, 2007), and being denied access or told to leave (Seelman, 2014b; Seelman et al., 2012). Further, different subgroups 
of transgender people may be at greater risk for these situations-Seelman (2014b) found that those who were people of color, had a disability, lived in a rural area, or were more often perceived by others as transgender were significantly more likely to be denied access to a school bathroom or other facility due to being transgender. Additionally, male-to-female (MTF) individuals were more likely than gender non-conforming people to have been denied access (Seelman, 2014b).

Fewer studies have detailed the experiences of transgender college students in accessing campus housing. Problematic practices include only offering gender-segregated housing, assigning housing and roommates based upon birth sex, not providing any singleoccupancy housing options, denying transgender students access to any housing, and not taking steps to ensure that housing is a place free of harassment and violence for all students (Beemyn, Curtis, Davis, \& Tubbs, 2005; Bilodeau, 2007; Finger, 2010; Seelman, 2014a, 2014b; Singh et al., 2013). Trans* individuals can experience distress in campus housing, particularly when there is a disconnect between their gendered presentation of self and assignment to gender-segregated campus housing (Pusch, 2005). Problematic situations include difficulties finding information about gender-inclusive housing options, trans* students being "outed" by others, and having decisions of whether to create gender-inclusive bathrooms decided by a majority vote among residents (Seelman et al., 2012). Seelman (2014b) found that those with lower current incomes were more likely to be denied access to gender-appropriate campus housing due to being transgender. MTF individuals were significantly more often denied gender-appropriate campus housing due to being transgender than were gender non-conforming individuals (Seelman, 2014b).

Scant research has examined the relationship between psychosocial well-being and institutional climate factors for trans* people in college settings, particularly using quantitative data. Bilodeau (2007) noted indications of "extreme stress" (p. 92) among 
transgender college students related to feeling that they need to be perceived by others as the gender listed on the bathroom in order to access the space without harassment. Findings from Colorado Trans on Campus (Seelman et al., 2012) indicate that when trans* identities are not represented or considered in bathroom designs, trans* students, staff, and faculty experience exclusion and invisibility, tend to feel less safe on campus, and try to avoid bathrooms on campus. Participants also reported not using bathrooms as frequently as they would if they felt safe and not drinking water on campus in order to avoid needing to use the bathroom (Seelman et al., 2012).

Participants from the Colorado study also spoke of exclusion and invisibility in relation to gender-segregated campus housing (Seelman et al., 2012). In discussing key recommendations, Seelman (2014a) notes how LGBTQ-specific campus housing that is meant to support this population of students is not always experienced as safe for trans* students, especially those who do not wish to widely disclose their gender identity, which likely contributes to symptoms of stress for this population. As stated by Beemyn (2005), not all trans* people are LGB or feel comfortable in LGBT-specific housing.

Next, I will detail the minority stress model, which helps provide conceptual grounding for looking at the relationship between being denied access to certain spaces due to being transgender and the relationship to individual well-being.

\section{Minority Stress Model}

The minority stress model (Meyer, 1995, 2003, 2007) posits that stigmatized groups face unique, chronic stressors due to the prejudice and discrimination prevalent in their social environment. The process of minority stress incorporates both distal stressors (external to the individual, such as violence or discrimination) and proximal stressors (internal to the individual, such as low self-worth related to a minority identity; Meyer, 2007). The model is intended to be flexibly applied so that researchers can understand how different stressors may 
impact subpopulations differently, such as comparing lesbian, gay, and bisexual (LGB) people by race and ethnicity (Meyer, 2007).

Although the minority stress model has been used predominantly with LGB people, a number of scholars have recently explored ways of applying this model to transgender individuals. For example, Hendricks and Testa (2012) discuss using the minority stress model in clinical psychology to understand the variety of stressful experiences transgender people experience related to discrimination, victimization, and internalized transphobia and the connection to psychological challenges, such as suicidality, as well as resiliency. Effrig et al. (2011) state that the minority stress theory can be helpful in studying transgender people because of the frequent occurrences of discrimination and harassment experienced by this population and the connection to psychological distress, such as suicidality.

Only a few studies have directly used the minority stress model to understand health outcomes for transgender people in relation to the stressful experiences of gender-segregated spaces. Herman (2013) appears to be one of the first to use this conceptual model in this way as part of an empirical study of 93 trans* adults' experiences in bathrooms. Among this sample, $68 \%$ had been verbally harassed and $9 \%$ physically assaulted while trying to use a public bathroom, and $18 \%$ had been denied access to a bathroom at some point in time. Physical health consequences included dehydration, being forced to wait for a longer period of time to use a bathroom, and kidney and urinary tract infections (Herman, 2013). Although Herman did not look at specific measures of mental health, the narratives of participants indicated a likely connection between bathroom stressors and mental well-being.

\section{Current Study}

While evidence indicates that trans* people face a variety of risks in college settings, including within gender-segregated bathrooms and housing on college campuses, we do not know much about whether negative experiences quantitatively relate to particular 
psychological risks for this population. Such evidence is key in helping college administrators to understand the relationship between characteristics of the institutional climate and outcomes of well-being for this population. As Herman (2013) articulates, studies using the minority stress model to examine gendered spaces are in need of sampling methods that are more generalizable than local convenience samples and more representation of trans* people of color. This study addresses these gaps by using a national, quantitative dataset of trans* people about their experiences in college settings and the relationship with suicidality.

The research question of interest is: Are experiences of institutional climate factors in higher education (denial of access to bathrooms or gender-appropriate campus housing) significantly associated with lifetime suicide attempts? Given the influence of interpersonal victimization on psychological health (Meyer, 2003), these relationships are examined while controlling for interpersonal victimization that occurred in college or graduate school.

\section{Methods}

This study uses secondary data from the National Transgender Discrimination Survey (NTDS), which was conducted by NCTE and the Task Force between September 2008 and March 2009 (Grant et al., 2011). This survey collected information from transgender and gender non-conforming individuals throughout the U.S. about their experiences of discrimination in a variety of settings. Participants were recruited via contacts with organizations around the country that either serve or are led by transgender people, as well as through 150 online discussion lists (Grant et al., 2011). The full sample $(\mathrm{N}=6,450)$ is the largest ever obtained for research about transgender people in the U.S. (Grant et al., 2011). The lead organizations provided the researcher with a copy of the de-identified dataset for research purposes, and the researcher received IRB approval for secondary data analysis from Georgia State University. The researcher used three filter variables to reduce this full sample to focus only on those who attended college while transgender: educational attainment 
(dropping those who had an education of a high school diploma or less), college attendance (dropping those who did not attend technical school, college, or graduate school), and gender identity in schools (dropping those who did not identify as trans* at any school level). This left 2,325 respondents for the analyses. Descriptive statistics for this subsample are detailed in the Results section.

\section{Measures}

Independent variables. Independent variables were selected based upon the minority stress model. The researcher included several demographic variables that frequently relate to suicidality, two college institutional climate factors related to the research question, and measures of interpersonal victimization. Two demographic variables that would likely play key roles but were not captured by the NTDS include time period (generation) when the respondent attended college and respondent's age while in college. While the NTDS did capture current age, this variable is only a weak stand-in for when a respondent might have attended college (assuming younger participants attended college most recently) and was not statistically significantly related to suicidality, so it was not included in the model.

Additionally, gender identity variables were not included in the model due to the complexity of categorizing survey respondents along this dimension and the impact this would have on model parsimony.

Block 1 of the logistic regression model includes the following demographic variables: (a) a dummy variable for race/ethnicity (White/person of color); (b) current annual household income (recoded into $\$ 10,000$ intervals, up to $\$ 100,000$ or above); and (c) three variables indicating disability status — whether one had a physical, learning, and/or mental disability other than a gender-related mental health diagnosis. The institutional climate factors consist of two dichotomous variables indicating: (a) whether one had been denied use of appropriate bathrooms or other facilities at school due to being transgender or gender non- 
conforming, and (b) whether one had been denied gender-appropriate housing on campus due to being transgender or gender non-conforming. While the phrase "gender-appropriate" was not defined on the survey, in this context the general meaning is understood as the housing most appropriate for one's gender identity (e.g., housing a trans man with other men). Two control variables are used to account for those who answered "not applicable" for either the bathroom or housing access questions to incorporate cases that would otherwise be treated as missing.

The interpersonal victimization variables in Block 2 of the regression model include: (a) a dummy variable indicating whether one had ever experienced harassment/bullying, physical assault/attack, or sexual assault by other students in college or graduate school due to being transgender or gender non-conforming; and (b) a dummy variable indicating whether one had ever experienced harassment/bullying, physical assault/attack, or sexual assault by teachers or staff in college or graduate school due to being transgender or gender nonconforming.

Dependent variable. The outcome variable of interest is a dichotomous measure indicating whether a respondent has ever attempted suicide.

\section{Statistical Analyses}

The researcher used SPSS version 19 to construct one sequential logistic regression model predicting suicidality. The independent variables generally had low amounts of missing data (less than $3 \%$ for each variable). The only variable that was missing not at random (MNAR) was the race/ethnicity dummy variable, which had missingness that was significantly related to suicidality. In situations where missingness is not random, researchers are advised to try to maintain all cases rather than drop the cases with missing data due to bias that can occur when dropping these cases (Tabachnick \& Fidell, 2007). Therefore, multiple imputation was used to predict values for all of the independent variables that had 
determinable missing data. Five imputations were calculated, which is thought to be adequate in cases where there are not large amounts of missing data (Rubin, 1996). The researcher compared the logistic regression models both before and after multiple imputation to look for differences in results. The models had highly similar output, with only very minor differences in the statistical significance of variables. Therefore, the imputed data model was utilized, and any differences between the two types of models are noted within the Results section.

\section{Results}

\section{Descriptive Statistics}

After dropping those in the NTDS sample whose education level was a high school diploma or less, who did not attend college, or who were never trans* while in a school setting, 2,325 respondents remained for the analyses. This includes students who attended college but have not yet earned a degree (35.4\% of the sample), some of whom may have dropped out before completion of a degree. Table 1 includes an overview of descriptive statistics for this sample. Some points of emphasis are that this sample trended younger, with a median age of 27 , which means that many respondents likely attended college in the past decade or so. The sample was majority white (73.3\%). More than 50\% had a current annual household income below $\$ 50,000$ per year. A large proportion $(24.9 \%)$ of those who had tried to access school bathrooms or other facilities while transgender had experienced denial of access to these spaces, while $20.8 \%$ had been denied access to gender-appropriate campus housing due to being trans*. Both of these percentages do not include those who either indicated that access to bathrooms $(n=595)$ or gender-appropriate campus housing $(n=972)$ was not applicable to their situation, presumably because they either did not try to access these locations or were not identifying or disclosing as trans* in these settings at the time. A key point to reiterate here is that "not being allowed to use" these spaces because of being trans* is vague phrasing and could encompass many different scenarios-from being 
Table 1

Sample Descriptive Statistics $(N=2,325)$

\begin{tabular}{|c|c|c|c|}
\hline Characteristic & $\begin{array}{c}\text { Descriptive } \\
\text { Statistics }\end{array}$ & Characteristic & $\begin{array}{c}\text { Descriptive } \\
\text { Statistics }\end{array}$ \\
\hline Race/ethnicity & & Annual Household Income & \\
\hline White & $73.3 \%$ & $<\$ 10 K$ & $18.6 \%$ \\
\hline Multiracial/Mixed race & $16.4 \%$ & $\$ 10 K-\$ 29,999$ & $27.5 \%$ \\
\hline Black/African American & $3.7 \%$ & $\$ 30 K-\$ 49,999$ & $21.0 \%$ \\
\hline Asian/Pacific Islander & $2.6 \%$ & $\$ 50 K-\$ 69,999$ & $12.7 \%$ \\
\hline Hispanic/Latino(a) & $2.5 \%$ & $\$ 70 K-\$ 89,999$ & $8.4 \%$ \\
\hline Other & $1.4 \%$ & $\$ 90 K$ \& above & $11.8 \%$ \\
\hline Age & & Has a physical disability & $16.3 \%$ \\
\hline $\begin{array}{l}M \\
(\mathrm{SD})\end{array}$ & $\begin{array}{c}31.02 \\
(10.32)\end{array}$ & Has a learning disability & $9.2 \%$ \\
\hline $\begin{array}{l}\text { Median } \\
\text { Range }\end{array}$ & $\begin{array}{c}27 \\
18-76\end{array}$ & $\begin{array}{l}\text { Has a mental disability } \\
\text { (other than gender-related } \\
\text { mental health diagnosis) }\end{array}$ & $23.5 \%$ \\
\hline Current gender identity & & & \\
\hline FTM transgender & $43.7 \%$ & & \\
\hline MTF transgender & $30.9 \%$ & Denied access to bathrooms & $24.9 \%$ \\
\hline F-to-other/gnc/part-time & $16.6 \%$ & & \\
\hline M-to-other/gnc/part-time & $2.2 \%$ & Denied access to gender- & \\
\hline F-to-crossdress male & $4.7 \%$ & appropriate campus housing & $20.8 \%$ \\
\hline M-to-crossdress female & $1.9 \%$ & & \\
\hline Educational Attainment & & Interpersonal victimization & \\
\hline Some college & $35.4 \%$ & in college or grad school & \\
\hline Tech school/Assoc. degree & $11.7 \%$ & From students & $30.2 \%$ \\
\hline Bachelor's degree & $33.7 \%$ & From teachers/staff & $13.8 \%$ \\
\hline \multirow[t]{2}{*}{ Some grad school or above } & $19.3 \%$ & & \\
\hline & & Suicide attempt & $46.5 \%$ \\
\hline
\end{tabular}

Note. Some percentages do not total $100 \%$ due to rounding.

questioned by students in bathrooms to being thrown out by security officials, for exampleand such differentiations may create very different psychological consequences. Further detail about this limitation is provided in the Discussion section. Suicide attempts (46.5\%) occurred at a rate higher than estimated for the general U.S. population, which has a selfreported lifetime suicide rate of approximately $4.6 \%$ (Nock \& Kessler, 2006).

Table 2 explores the predictor variables of interest by lifetime suicide attempt. The prevalence of suicide attempt by mental disability is particularly striking, with $68 \%$ of those with a mental disability other than a gender-related mental health diagnosis having attempted 
Table 2

Lifetime suicide attempt prevalence by demographic characteristics, access to campus spaces, and interpersonal victimization.

\begin{tabular}{|c|c|c|}
\hline Characteristic & $\begin{array}{c}\text { Suicide attempt } \\
(n=1,077), \text { No. }(\%)\end{array}$ & $\begin{array}{l}\text { No suicide attempt } \\
(n=1,239) \text {, No. }(\%)\end{array}$ \\
\hline Race/ethnicity & & \\
\hline Person of color & $312(51.1 \%)$ & $299(48.9 \%)$ \\
\hline White & $748(44.4 \%)$ & $935(55.6 \%)$ \\
\hline $\begin{array}{l}\text { Annual Income } \\
\text { Less than } \$ 30,000 \\
\$ 30,000 \text { and up }\end{array}$ & $\begin{array}{l}554(53.1 \%) \\
498(40.7 \%)\end{array}$ & $\begin{array}{l}489(46.9 \%) \\
725(59.3 \%)\end{array}$ \\
\hline $\begin{array}{l}\text { Physical Disability } \\
\text { Yes } \\
\text { No }\end{array}$ & $\begin{array}{l}224(59.1 \%) \\
853(44.0 \%)\end{array}$ & $\begin{array}{c}155(40.9 \%) \\
1084(56.0 \%)\end{array}$ \\
\hline Learning Disability & & \\
\hline Yes & $124(58.2 \%)$ & $89(41.8 \%)$ \\
\hline No & $953(45.3 \%)$ & $1150(54.7 \%)$ \\
\hline Mental Disability & & \\
\hline Yes & $368(67.5 \%)$ & $177(32.5 \%)$ \\
\hline No & $709(40.0 \%)$ & $1062(60.0 \%)$ \\
\hline $\begin{array}{c}\text { Bathrooms/Facilities }^{\mathrm{a}} \\
\text { Denied access } \\
\text { Not denied }\end{array}$ & $\begin{array}{l}257(60.5 \%) \\
553(43.2 \%)\end{array}$ & $\begin{array}{l}168(39.5 \%) \\
728(56.8 \%)\end{array}$ \\
\hline $\begin{array}{l}\text { Gender-Appropriate } \\
\text { Campus Housing }\end{array}$ & & \\
\hline $\begin{array}{l}\text { Denied housing } \\
\text { Not denied }\end{array}$ & $\begin{array}{l}166(60.6 \%) \\
438(41.8 \%)\end{array}$ & $\begin{array}{l}108(39.4 \%) \\
611(58.2 \%)\end{array}$ \\
\hline $\begin{array}{l}\text { Victimization by } \\
\text { college students }\end{array}$ & & \\
\hline $\begin{array}{l}\text { Yes } \\
\text { No }\end{array}$ & $\begin{array}{l}385(55.1 \%) \\
692(42.8 \%)\end{array}$ & $\begin{array}{l}314(44.9 \%) \\
925(57.2 \%)\end{array}$ \\
\hline $\begin{array}{l}\text { Victimization by } \\
\text { college teachers/staff } \\
\text { Yes } \\
\text { No }\end{array}$ & $\begin{array}{l}190(59.0 \%) \\
887(44.5 \%)\end{array}$ & $\begin{array}{c}132(41.0 \%) \\
1107(55.5 \%)\end{array}$ \\
\hline
\end{tabular}

a The frequencies for denial of access to bathrooms/facilities and campus housing displayed here do not include those who responded "Not applicable."

suicide, compared to $40 \%$ of those without a mental disability. Suicide attempt rates by denial of access to campus bathrooms $(61 \%)$ and gender-appropriate housing $(61 \%)$ are also worth noting. 


\section{Inferential Statistics}

One sequential logistic regression model was constructed predicting suicide attempts. The first block contained demographic variables and the two college institutional climate variables (denial of access to bathrooms/facilities and denial of access to gender-appropriate campus housing due to being transgender). The second block included the interpersonal victimization variables.

The model with the demographic and institutional climate variables (Block 1) was a statistically significant improvement over the constant-only model before multiple imputation (see Table 3). Additionally, the Hosmer and Lemeshow Test suggests the model has good fit, indicated by a $p$ value $>.05$ (also in Table 3 ).

After imputation, 2,316 cases remained for analysis through the logistic regression model. Any differences between the model before and after imputation are noted underneath Table 4. Within Block 1 of the model (see Table 4), race, annual household income, having a physical or mental disability, being denied access to a school bathroom due to being transgender, and being denied access to gender-appropriate campus housing due to being transgender were all statistically significantly related to lifetime suicide attempt. Compared to White trans* individuals, trans* people of color are 1.24 times as likely to have attempted suicide. For every $\$ 10,000$ increase in current annual household income (up to $\$ 100,000$ ), the risk of suicide attempt is predicted to decrease by $6 \%$. Compared to those without a disability, those who had a physical disability are 1.47 times as likely to have attempted suicide, and those with a mental disability other than a gender-related mental health diagnosis are 2.69 times as likely to have attempted suicide. Controlling for people who responded "not applicable" to the bathroom access question, those who had been denied access to a school bathroom or other facility due to being trans* are $1.45^{2}$ times as likely to

\footnotetext{
${ }^{2}$ This statistic was calculated using the inverse odds ratio: $1 / 0.69=1.45$.
} 
Table 3

Omnibus Test of Model Coefficients, Nagelkerke $R^{2}$ and Hosmer and Lemeshow Test for Blocks 1 and 2 of the Logistic Regression Model Before Multiple Imputation

\begin{tabular}{lcc}
\hline & \multicolumn{2}{c}{$\begin{array}{c}\text { Suicide Attempt } \\
(N=2,218)\end{array}$} \\
\hline & Block 1 & Block 2 \\
\hline $\begin{array}{l}\text { Omnibus Test of Model Coefficients } \\
\text { for each block }\left(\chi^{2}\right)\end{array}$ & $\begin{array}{c}209.13^{* * *} \\
(d f=9)\end{array}$ & $\begin{array}{c}18.61^{* * *} \\
(d f=2)\end{array}$ \\
\hline \multicolumn{1}{l}{$\begin{array}{l}\text { Nagelkerke } R^{2} \\
\begin{array}{l}\text { Hosmer and Lemeshow } \\
\left(\chi^{2}, d f=8\right)\end{array}\end{array}$} & .12 & .13 \\
\hline $\bar{\dagger}^{\dagger}>.05 . * * * p<.001$. & $12.37^{\dagger}$ & $10.29^{\dagger}$ \\
\hline
\end{tabular}

have attempted suicide at some point in time compared to those who were not denied access to a school bathroom or facility. Additionally, those who had been denied access to genderappropriate campus housing due to being trans* are 1.64 times as likely to have attempted suicide than those who had not been denied access to gender-appropriate housing, controlling for those who responded "not applicable" to this question.

Adding the interpersonal victimization variables in Block 2 was a statistically significant improvement over the constant-only model, according to the omnibus test of model coefficients (see Table 3). In Block 2, the same variables that were statistically significant in Block 1 remained significant, even after controlling for victimization by students and teachers/staff (see Table 4). Compared to White trans* individuals, trans* people of color were 1.25 times as likely to have attempted suicide. For every $\$ 10,000$ increase in current annual household income (up to $\$ 100,000$ ), the risk of suicide attempt is predicted to decrease by $6 \%$. Compared to those without a disability, those who had a 
Table 4

Sequential Logistic Regression Model for Suicide Attempts (Pooled Data after Multiple Imputation, $\mathrm{N}=2,316$ )

\begin{tabular}{|c|c|c|c|c|}
\hline \multirow[t]{2}{*}{ Predictor Variables } & \multicolumn{2}{|c|}{ Block 1} & \multicolumn{2}{|c|}{ Block 2} \\
\hline & $\begin{array}{c}B \\
\text { (s.e.) }\end{array}$ & $\begin{array}{l}\text { Odds } \\
\text { Ratio }\end{array}$ & $\begin{array}{c}B \\
\text { (s.e.) }\end{array}$ & $\begin{array}{l}\text { Odds } \\
\text { Ratio }\end{array}$ \\
\hline \multicolumn{5}{|l|}{$\begin{array}{l}\text { Demographics \& College } \\
\text { Institutional Climate }\end{array}$} \\
\hline Race/ethnicity & $\begin{array}{l}0.21 * \mathrm{a} \\
(0.10)\end{array}$ & 1.24 & $\begin{array}{l}0.23 * \\
(0.10)\end{array}$ & 1.25 \\
\hline Annual household income & $\begin{array}{c}-0.06 * * * \\
(0.01)\end{array}$ & 0.94 & $\begin{array}{c}-0.06 * * * \\
(0.01)\end{array}$ & 0.94 \\
\hline Physical Disability & $\begin{array}{l}0.38 * * \\
(0.12)\end{array}$ & 1.47 & $\begin{array}{l}0.36 * * \\
(0.12)\end{array}$ & 1.44 \\
\hline Learning Disability & $\begin{array}{c}0.16 \\
(0.16)\end{array}$ & 1.17 & $\begin{array}{c}0.14 \\
(0.16)\end{array}$ & 1.15 \\
\hline Mental Disability & $\begin{array}{c}0.99 * * * \\
(0.11)\end{array}$ & 2.69 & $\begin{array}{c}0.99 * * * \\
(0.11)\end{array}$ & 2.70 \\
\hline $\begin{array}{l}\text { Denied access school } \\
\text { bathroom }\end{array}$ & $\begin{array}{l}-0.38 * * \\
(0.14)\end{array}$ & 0.69 & $\begin{array}{l}-0.28^{*} \\
(0.14)\end{array}$ & 0.76 \\
\hline Bathroom access n/a & $\begin{array}{l}-0.52 * * \\
(0.17)\end{array}$ & 0.60 & $\begin{array}{c}-0.42 * \mathrm{a} \\
(0.17)\end{array}$ & 0.66 \\
\hline $\begin{array}{l}\text { Denied gender-appropriate } \\
\text { campus housing }\end{array}$ & $\begin{array}{l}-0.50 * * \\
(0.17)\end{array}$ & 0.61 & $\begin{array}{c}-0.43 * \mathrm{a} \\
(0.17)\end{array}$ & 0.65 \\
\hline $\begin{array}{l}\text { Gender-appropriate housing } \\
\text { access n/a }\end{array}$ & $\begin{array}{l}-0.27 \\
(0.17)\end{array}$ & 0.76 & $\begin{array}{l}-0.17 \\
(0.18)\end{array}$ & 0.84 \\
\hline \multicolumn{5}{|l|}{ Interpersonal Victimization } \\
\hline Victimization by students & & & $\begin{array}{l}0.31 * * \\
(0.10)\end{array}$ & 1.36 \\
\hline $\begin{array}{l}\text { Victimization by } \\
\text { teachers/staff }\end{array}$ & & & $\begin{array}{l}0.26^{\wedge} \\
(0.14)\end{array}$ & 1.29 \\
\hline (Constant) & $\begin{array}{c}0.48 \\
(0.162)\end{array}$ & & $\begin{array}{c}0.19 \\
(0.17)\end{array}$ & \\
\hline
\end{tabular}

$\bar{a}$ There were a few minor differences in output between the original and imputed data. Race, which was marginal before imputation in Block 1, became statistically significant after imputation; since race was missing not at random, imputation of this variable was particularly important. The change in result may reflect either a more accurate accounting of this relationship between race and suicide attempts or an overestimate of the relationship in Block 1. Nonetheless, race's significance in Block 2 was the same before and after imputation. Other than a slight change in the degree of statistical significance of two variables in Block 2 (the "Not Applicable" bathroom access control variable and the gender-appropriate housing variable, both of which had $p$ values that changed from $<.01$ to $<.05$ after imputation), the original and imputed data models produced highly similar output in Block 2.

${ }^{\wedge} p<.10 . * p<.05 . * * p<.01 . * * * p<.001$. 
physical disability are 1.44 times as likely to have attempted suicide, while those with a mental disability other than a gender-related mental health diagnosis are 2.7 times as likely to have attempted suicide. Those who had been denied access to a school bathroom or other facility due to being trans* are 1.32 times as likely to have attempted suicide at some point in time compared to those who were not denied access to a school bathroom or facility, controlling for those who answered "not applicable" to this question. Those who had been denied access to gender-appropriate campus housing due to being trans* are 1.54 times more likely to have attempted suicide than those who had not been denied housing, controlling for the "not applicable" respondents. Interpersonal victimization by students in college or graduate school is a statistically significant predictor of suicide attempt: those who had experienced harassment, bullying, physical attack, or sexual assault from other students are 1.36 times as likely to have attempted suicide at some point in time compared to those who had not experienced such victimization in college.

\section{Discussion}

The NTDS is the largest survey to date of transgender and gender non-conforming people in the U.S., and the data have provided much-needed empirical information about discrimination affecting this population across multiple sectors of their lives. Using a subsample of participants from this survey, the present study sheds light on how the minority stress model might be used to understand how institutional climate factors in college settings (specifically, bathrooms and campus housing that are not accessible to transgender people) relate to psychological well-being in the form of lifetime suicide attempts. One point of emphasis is that this sample tended to consist of younger adults, with a median age of 27 , which means that many participants had likely attended college in the past decade or so. Therefore, results are likely most reflective of the experiences of recent college students. 
The NTDS data indicate that a sizeable portion of trans* people continue to face a multitude of interpersonal stressors in college, as nearly one-third of this sample had experienced harassment, bullying, or physical or sexual assault by other students and $13.8 \%$ had experienced such victimization at the hands of teachers or staff in college or graduate school. College administrators, faculty, and staff could benefit from understanding how rampant such issues are and considering ways of effectively addressing harassment and victimization, such as through a trained network of staff and faculty on campus who specialize in understanding, preventing, and responding to these issues and providing support to students experiencing victimization (Rankin et al., 2010; Seelman, 2014a; Seelman et al., 2012). Scholars have called for having no-tolerance policies in place to better prevent and respond to harassment and assault impacting trans* individuals, with well-defined consequences for perpetrators and purposeful work to prevent future incidents (Beemyn \& Rankin, 2011; Rankin et al., 2010; Seelman, 2014a; Seelman et al., 2012). Students who do not feel safe on campus are likely less invested in remaining at that particular college and may drop out (Rankin et al., 2010) or transfer to campuses that are more welcoming, which has an impact on a college's financial bottom line.

In addition to interpersonal victimization, a number of the participants $(25 \%)$ had been denied access to bathrooms or other facilities in school due to being transgender or gender non-conforming. While the survey did not collect information about precisely what "not being allowed to use" appropriate bathrooms looked like, previous studies have indicated that trans* people can face questioning, harassment, and denial of access from a variety of groups of people, from fellow students to staff, faculty, and campus police (Bilodeau, 2007; Finger, 2010; Seelman et al., 2012). The survey did not collect precise information about whether respondents' campuses had any bathroom/facilities policies that are meant to improve access and safety for trans* people, such as gender-inclusive 
bathrooms. However, one might hypothesize that students who had access to genderinclusive bathrooms were less likely to be "denied" access because such spaces are intended to be open to everyone, regardless of gender identity or gender expression.

About one-fifth (21\%) of the sample had been denied access to gender-appropriate campus housing due to being trans*. While not precisely defined for survey respondents, one could conjecture that being denied "gender-appropriate" housing would encompass situations where transgender students were provided housing, but it did not align with their gender identity (e.g., a trans women being housed with male students). Advocates and researchers have identified this as a common problem that creates distress for trans* students (Beemyn, Domingue, Pettitt, \& Smith., 2005; Finger, 2010; Seelman, 2013; Singh et al., 2013). Denial of access to gender-appropriate housing is likely occurring at the hands of staff/administrators who handle campus housing assignments. Considering that the prevalence of this discrimination is notable within this sample, college administrators should work to ensure that all students who wish to access campus housing are on equal footing for access to safe, gender-appropriate options, regardless of whether they are trans* or not.

A remarkably high proportion of the sample $(46.5 \%)$ had a history of attempting suicide, which is higher than the $41 \%$ rate found for the full NTDS sample (Grant et al., 2011). As noted earlier, this suicide attempt rate is higher than that of the general U.S. population and supports the premise that minority populations are going to show indicators of experiencing heightened stress. This further emphasizes the importance of having wellfunded and trans*-competent mental health services in college settings to best meet the needs of this population, whether they have a history of attempting suicide when arriving on campus or are at risk for this behavior while in college.

Turning to the logistic regression model, certain subgroups were at greater risk for suicide attempts, including those who had lower current income, those with a physical or 
mental disability, and individuals of color. These differences remain even when controlling for college institutional factors and interpersonal victimization. These findings are important in understanding that different subgroups of trans* people experience life differently and have varying needs for support. The finding related to race is important, given that some previous research has found that suicide attempts may happen more often for White transgender individuals than for people of color (Clements-Nolle et al., 2006). For those working in higher education, there is value in paying attention to the whole person who may be seeking support for dealing with stressors, rather than assuming all trans* people have the same challenges (Finger, 2010; Seelman, 2013). Understanding the ways in which race, ethnicity, socioeconomic status, and disability status - and the associated experiences of discrimination and violence — contribute to psychological distress for trans* people are important areas for continued research. Importantly, the three disability variables in this study simply asked respondents to report if they had a physical condition, learning disability, or mental health condition that affects a major life activity, but did not include validated measures to detect diagnoses or ask for further detail about which conditions a person had. Thus, these participants may have had conditions ranging from diagnosed depression to ADHD to Parkinson's disease, which may have very different connections to suicide risk. Interpersonal victimization by fellow students — but not teachers/staff — was significantly associated with suicidality. Victimization by students related to suicidality as one would expect from the minority stress model - that is, those who face greater stressors related to harassment, prejudice and assault from peers are at greater risk for psychological distress, in this case indicated by at least one suicide attempt. However, information was not collected about whether the suicide attempt occurred before, concurrently, or after enrollment in college. Thus, the data do not say whether harassment preceded suicidality, or vice versa. Nonetheless, higher education staff and faculty can benefit from understanding the 
relationship between interpersonal victimization from peers and suicidality, whether it means that people with a previous suicide attempt are more likely to later experience victimization or those who experience victimization are more likely to later attempt suicide.

While victimization by teachers was not statistically significant, it approached statistical significance in the expected direction. This variable's influence may be underestimated due to an artifact of how the question was asked—missing data could not be distinguished from "no" responses to the victimization questions because these questions were measured using check boxes to indicated victimization had occurred. While the variable measuring victimization by students was measured in the same way, it also had a larger proportion of "yes" responses, indicating a lower likelihood that missing data were incorrectly categorized as "no harassment" responses. Further, a number of those who had experienced victimization by teachers had also experienced victimization by students $(68.9 \%)$. Thus, when the logistic regression model controls for victimization by students, this may underestimate the unique impact of victimization by teachers/staff in predicting suicide attempts.

Within the logistic regression model, the finding of most interest to the research question was that both denial of access to bathrooms and denial of access to campus housing due to being trans* were statistically significantly associated with lifetime suicide attempt. These results held even when controlling for interpersonal victimization in college. This suggests that there may be a distinct relationship between the stress of not being able to use bathrooms or gender-appropriate campus housing and one's mental health. This evidence is an initial step in supporting the idea that institutional climate factors such as gendersegregated bathrooms - although perhaps not intended to be hurtful — may negatively affect the well-being of trans* people. These data support the emerging research base that lack of 
access to gender-appropriate housing and bathrooms can increase stress and negatively impact health for trans* people (Bilodeau, 2007; Herman, 2013; Seelman et al., 2012).

\section{Limitations}

The present study has several limitations. First, the NTDS did not utilize random sampling, which is not feasible with hard-to-access populations such as trans* people. This limits the generalizability of results - the data captured by this survey more likely reflect the experiences of trans* people who are most connected to local and national transgenderserving organizations. Trans* people who are not as connected to such organizationsincluding older generations and people who might not use the term "transgender" to describe themselves - may not be captured by the survey. Further, because the survey had "discrimination" in the title, those who participated may report higher rates of discrimination than would occur among a random sample of trans* people. Nonetheless, the NTDS is the largest survey of trans* people conducted in the U.S. to date, and the geographic dispersion of the sample is similar to the population distribution in the U.S. (Grant et al., 2011).

Second, this survey was distributed at one point in time, and information was not collected about when precisely participants experienced suicidality — they may have experienced suicide attempts before, during, or after attending college. Therefore, we cannot interpret causality from the data models (e.g., that denial of access to campus housing and bathrooms causes suicidality, etc.). Relatedly, while the survey collected information about respondents' current age, it did not request information about when participants attended college, what type of institution they attended, whether they were currently enrolled, or whether they dropped out. Thus, some valuable pieces of information were missing from these data that may act to influence the likelihood of denial of access to campus spaces or moderate the relationship between this and the outcome variables. In particular, the survey could have been strengthened by asking about when participants last attended college, since 
experiences of discrimination likely differ between generations due to the increasing visibility of the transgender population and changing policy landscape. Further, we cannot tell from the survey questions whether denial of access to campus spaces happened as part of a generally exclusionary environment or if it was related to how other people reacted to an individual's gender expression.

Third, there are likely many lifetime factors that can contribute to psychological distress for trans* people that were not captured by the data analysis models here. The focus in this article was on college climates, but there are many other sectors of a person's life (family, previous schooling, social life, etc.) that could present additional stress. Further, there are likely a multitude of protective factors that can help buffer trans* people from psychological distress, and such factors were not captured in these analyses. These limitations affect the overall scope of the findings, as indicated by the relatively low Nagelkerke $R^{2}$ values of the logistic regression.

Lastly, the questions measuring access to bathrooms and housing were worded vaguely and did not precisely specify the level of schooling in which participants may have been denied access to these spaces. While these questions were placed alongside other questions relevant primarily to higher education (e.g., financial aid) and the question about housing is likely only applicable for the college environment for most people, there is still the possibility that participants may have been thinking of other school settings. To help address this issue, the analyses here only utilized those in the sample who had attended college and identified as trans* in that setting. Nonetheless, some inaccuracy may remain in terms of the schooling setting being measured by those two questions.

\section{Implications}

This study has implications for both future research and for those working in higher education settings who wish to best support trans* individuals. While this research indicates a 
relationship between college institutional climate factors and suicidality, there is a continued need for in-depth exploration of stressors related to being denied access to housing and bathrooms and other experiences of discrimination in these settings beyond the college climate. For example, are the patterns seen in this study similar to those that might be seen in other education settings? What about for public bathrooms or housing outside of education settings? The current study focused only on suicide attempts, but future research could shed further light on other psychological and physical health outcomes that build from Herman's research (2013).

As discussed earlier, this survey did not allow for cross-generational comparisons of college climates and health consequences for various cohorts of college students. The knowledge base could benefit from understanding the ways that outcomes might vary between generations and how college climates have changed over time. Additionally, longitudinal studies could help better examine causality between campus climate and psychosocial outcomes and explore the long-term impacts of discrimination and harassment. How do trans* people speak about mental health struggles that may result over the longterm? What are the situations over time that create risks for suicidality as a consequence of discrimination and stress? Additionally, future research might look at some of the protective factors and forms of resilience — both at an individual and an institutional level—that help buffer trans* people against negative health outcomes. Importantly, several scholars have been calling for and initiating studies of transgender resilience, coping, and advocacy (Burdge, 2014; Case et al., 2012; Singh, 2013; Singh, Hays, \& Watson, 2011; Singh \& McKleroy, 2011; Singh et al., 2013).

For those working in higher education settings, the findings suggest that characteristics of the college institutional climate related to gender-segregated spaces are associated with well-being for trans* people. These issues align with many campuses’ 
nondiscrimination policies and overall commitment to creating safe campuses for all students. Even if administrators do not intend for trans* people to be excluded on campus through the existence of gender-segregated bathrooms and housing policies, trans* people still experience harm when they are denied access to these spaces, which is likely to contribute to dropout rates and weakened academic performance. Further, certain subgroups of trans people who bring other marginalized identities on campus tend to be at greater risk for experiences of suicidality. Other research has shown that marginalized subgroups are also more likely to experience the denial of access to bathrooms and campus housing (Seelman, 2014b), less faculty mentoring, and detrimental educational outcomes (Dugan et al., 2012).

The present study offers further evidence supporting the need for institutional climate changes in higher education (Beemyn, Domingue, et al., 2005; Bilodeau, 2007; Dugan et al., 2012; Finger, 2010; Rankin et al., 2010; Seelman, 2015; Seelman et al., 2012; Singh et al., 2013), such as changing facilities so that there are some gender-inclusive facilities and housing options (open to all genders) whose presence is well-advertised to all students, staff, and faculty. This does not mean that all facilities need to be made gender-inclusive, but, for example, providing at least one gender-inclusive bathroom in each building and at least one gender-inclusive campus housing option can make a difference. Additionally, efforts can also be made to educate the general campus population that it is not okay to deny access to bathrooms or housing based on a person's gendered appearance. Rather, behavior (e.g., assault, harassment) is what should be used to determine whether someone should be removed from such a space (Seelman, 2014a).

Findings point to the need for ensuring that students of all gender identities have an ability to find safe, gender-appropriate housing on campus, such as the option to room with peers of any gender or to choose single-occupancy rooms, if desired. Further, by having policies that prohibit discrimination on the basis of gender identity and gender expression, 
campuses can communicate their support for ensuring housing for trans* students in a formal way. Additionally, recent guidance from the U.S. Department of Education (2014b) has indicated that Title IX encompasses protection of transgender students from discrimination, which impacts any college or university receiving federal dollars. This includes making sure each person's gender identity is respected when accessing college bathrooms and housing. Administrators who take steps to combat discrimination affecting trans* people as well as other marginalized groups are not only contributing to a safer climate for these populations but also communicating the institution's commitment to inclusiveness and the development of a diverse campus population.

\section{Conclusion}

Few scholars have utilized the minority stress model to examine the relationship between college climate factors, such as denial of access to bathrooms or housing, and individual psychological outcomes for trans* people. The present study's goal was to contribute to this area of research using a national dataset of trans* individuals. Findings indicate relationships between denial of access to bathrooms and gender-appropriate campus housing and increased risk for suicidality, even after controlling for interpersonal victimization in college. These results suggest that the set-up of a college campus connects to the well-being of trans* students, whether or not the campus has intended to actively deny this population access to campus spaces. Administrators and advocates can use these findings to help call for changes to college and university settings so that they more effectively support and welcome people who are trans*. 


\section{References}

Beemyn, B. (2005). Making campuses more inclusive of transgender students. Journal of Gay \& Lesbian Issues in Education, 3(1), 77-87. doi: 10.1300/J367v03n01_08

Beemyn, B., Curtis, B., Davis, M., \& Tubbs, N. J. (2005). Transgender issues on college campuses. New Directions for Student Services, 111, 49-60. doi: 10.1002/ss.173

Beemyn, B. G., Domingue, A., Pettitt, J., \& Smith, T. (2005). Suggested steps to make campuses more trans-inclusive. Journal of Gay and Lesbian Issues in Education, 3(1), 89-94. doi:10.1300/J367v03n01

Beemyn, G., \& Rankin, S. R. (2011). The lives of transgender people. New York, NY: Columbia University Press.

Bilodeau, B. (2005). Beyond the gender binary: A case study of two transgender students at a Midwestern research university. Journal of Gay \& Lesbian Issues in Education, 3(1), 29-44. doi:10.1300/J367v03n01

Bilodeau, B. L. (2007). Genderism: Transgender students, binary systems and higher education (Doctoral dissertation). Retrieved from ProQuest Dissertations and Theses Database. (UMI No. 3264140)

Burdge, B. J. (2014). Being true, whole, and strong: A phenomenology of transgenderism as a valued life experience. Journal of Gay \& Lesbian Social Services, 26(3), 355-382. doi:10.1080/10538720.2014.926232

Case, K. A., Kanenberg, H., Erich, S., \& Tittsworth, J. (2012). Transgender inclusion in university nondiscrimination statements: Challenging gender-conforming privilege through student activism. Journal of Social Issues, 68(1), 145-161. doi:10.1111/j.1540-4560.2011.01741.x 
Clements-Nolle, K., Marx, R., \& Katz, M. (2006). Attempted suicide among transgender persons: The influence of gender-based discrimination and victimization. Journal of Homosexuality, 51(3), 53-69. doi:10.1300/J082v51n03_04

Dugan, J. P., Kusel, M. L., \& Simounet, D. M. (2012). Transgender college students: An exploratory study of perceptions, engagement, and educational outcomes. Journal of College Student Development, 53(5), 719-736. doi:10.1353/csd.2012.0067

Effrig, J. C., Bieschke, K. J., \& Locke, B. D. (2011). Examining victimization and psychological distress in transgender college students. Journal of College Counseling, 14(2), 143-157. doi:10.1002/j.2161-1882.2011.tb00269.x

Finger, E. F. (2010). Beyond the binary: Serving the transgender student, improving the college experience (Doctoral dissertation). Retrieved from ProQuest Dissertations and Theses database. (UMI No. 3445367)

Goldblum, P., Testa, R. J., Pflum, S., Hendricks, M. L., Bradford, J., \& Bongar, B. (2012). The relationship between gender-based victimization and suicide attempts in transgender people. Professional Psychology: Research and Practice, 43(5), 468-475. doi:10.1037/a0029605

Grant, J. M., Mottet, L. A., Tanis, J., Harrison, J., Herman, J. L., \& Keisling, M. (2011). Injustice at every turn: A report of the National Transgender Discrimination Survey. Washington, DC: National Center for Transgender Equality and the National Gay and Lesbian Task Force. Retrieved from http://transequality.org/PDFs/NTDS_Report.pdf Hendricks, M. L., \& Testa, R. J. (2012). A conceptual framework for clinical work with transgender and gender nonconforming clients: An adaptation of the Minority Stress Model. Professional Psychology: Research and Practice, 43(5), 460-467. doi:10.1037/a0029597 
Herman, J. L. (2013). Gendered restrooms and minority stress: The public regulation of gender and its impact on transgender people's lives. Journal of Public Management \& Social Policy, 65-80. Retrieved from: http://williamsinstitute.law.ucla.edu/research/ transgender-issues/herman-jpmss-june-2013/

Lombardi, E. (2009). Varieties of transgender/transsexual lives and their relationship with transphobia. Journal of Homosexuality, 56(8), 977-92. doi:10.1080/00918360903275393

McKinney, J. (2005). On the margins: A study of the experiences of transgender college students. Journal of Gay \& Lesbian Issues in Education, 3(1), 63-76. doi:10.1300/J367v03n01_07

Meyer, I. H. (1995). Minority stress and mental health in gay men. Journal of Health and Social Behavior, 36(1), 38-56. doi: 10.2307/2137286

Meyer, I. H. (2003). Prejudice, social stress, and mental health in lesbian, gay, and bisexual populations: conceptual issues and research evidence. Psychological Bulletin, 129(5), 674-97. doi:10.1037/0033-2909.129.5.674

Meyer, I. H. (2007). Prejudice and discrimination as social stressors. In I. H. Meyer \& M. E. Northridge (Eds.), The health of sexual minorities: Public health perspectives on lesbian, gay, bisexual and transgender populations (pp. 242-267). New York, NY: Springer.

Nock, M. K., \& Kessler, R. C. (2006). Prevalence of and risk factors for suicide attempts versus suicide gestures: Analysis of the National Comorbidity Survey. Journal of Abnormal Psychology, 115, 616-623. doi: 10.1037/0021-843X.115.3.616

Pusch, R. S. (2005). Objects of curiosity: Transgender college students' perceptions of the reactions of others. Journal of Gay \& Lesbian Issues in Education, 3(1), 45-61. doi:10.1300/J367v03n01 
Rankin, S., Weber, G., Blumenfeld, W., \& Frazer, S. (2010). 2010 State of higher education for lesbian, gay, bisexual \& transgender people. Charlotte, NC.

Rubin, D. B. (1996). Multiple imputation after 18+ Years. Journal of the American Statistical Association, 91(434), 473-489. doi: 10.1080/01621459.1996.10476908

Seelman, K. L. (2013). A mixed methods examination of structural bigenderism and the consequences for transgender and gender variant people (Doctoral dissertation). Retrieved from ProQuest Dissertations and Theses Database. (UMI No. 3588397).

Seelman, K. L. (2014a). Recommendations of transgender students, staff, and faculty in the USA for improving college campuses. Gender \& Education. Advance online publication. doi: 10.1080/09540253.2014.935300

Seelman, K. L. (2014b). Transgender individuals' access to college housing and bathrooms: Findings from the National Transgender Discrimination Survey. Journal of Gay \& Lesbian Social Services, 26(2), 186-206. doi: 10.1080/10538720.2014.891091

Seelman, K. L., Walls, N. E., Costello, K., Steffens, K., Inselman, K., Montague-Asp, H., and Colorado Trans on Campus Coalition. (2012). Invisibilities, uncertainties, and unexpected surprises: The experiences of transgender and gender non-conforming students, staff, and faculty at colleges and universities in Colorado. Denver, CO: Authors. Retrieved from: https://portfolio.du.edu/ewalls2

Singh, A. A. (2013). Transgender youth of color and resilience: Negotiating oppression and finding support. Sex Roles, 68(11-12), 690-702. doi:10.1007/s11199-012-0149-z

Singh, A. A., Hays, D. G., \& Watson, L. S. (2011). Strength in the face of adversity: Resilience strategies of transgender individuals. Journal of Counseling \& Development, 89(1), 20-27. doi:10.1002/j.1556-6678.2011.tb00057.x 
Singh, A. A., \& McKleroy, V. S. (2011). "Just getting out of bed is a revolutionary act": The resilience of transgender people of color who have survived traumatic life events. Traumatology, 17(2), 34-44. doi:10.1177/1534765610369261

Singh, A. A., Meng, S., \& Hansen, A. (2013). "It's already hard enough being a student": Developing affirming college environments for trans youth. Journal of LGBT Youth, 10(3), 208-223. doi:10.1080/19361653.2013.800770

Substance Abuse and Mental Health Services Administration (SAMHSA). (2012). Top health issues for LGBT populations information \& resource kit. Retrieved from http://store.samhsa.gov

Tabachnick, B. G., \& Fidell, L. S. (2007). Using multivariate statistics (5th ed.). Boston, MA: Pearson Education.

Testa, R. J., Sciacca, L. M., Wang, F., Hendricks, M. L., Goldblum, P., Bradford, J., \& Bongar, B. (2012). Effects of violence on transgender people. Professional Psychology: Research and Practice, 43(5), 452-459. doi:10.1037/a0029604

U.S. Department of Education, National Center for Education Statistics. (2014a). Digest of education statistics: Table 302.10 Recent high school completers and their enrollment in 2-year and 4-year colleges, by sex: 1960 through 2013. Retrieved from http://nces.ed.gov/programs/digest/d14/tables/dt14_302.10.asp

U.S. Department of Education, Office for Civil Rights. (2014b). Questions and answers on Title IX and sexual violence. Retrieved from http://www2.ed.gov/about/offices/ list/ocr/docs/qa-201404-title-ix.pdf 